\title{
A descriptive study of 100 patients undergoing palliative nerve blocks for chronic intractable headache and neck ache
}

\author{
Peter Rothbart MD FRCPC DABPM ${ }^{1}$, Katherine Fiedler PhD LCSW-C ${ }^{2}$, George D Gale MBBS FRCPC DAAPM ${ }^{1}$, \\ David Nussbaum PhD CPsych ${ }^{3}$, Nelson Hendlerb MD MS ${ }^{2}$
}

P Rothbart, K Fiedler, GD Gale, D Nussbaum, N Hendlerb. A descriptive study of 100 patients undergoing palliative nerve blocks for chronic intractable headache and neck ache. Pain Res Manage 2000;5(4):243-248.

OBJECTIVE: To ascertain whether repeated (palliative) nerve blocks over a long period of time provide benefit to patients with chronic intractable headache and neck ache.

SUBJECTS AND METHODS: One hundred patients who were receiving repeated nerve blocks as part of their pain management regimen completed a structured interview questionnaire. The patients had all been investigated and received a diagnosis of cervicogenic headache. Changes in pain rating, depression rating, anxiety rating, activities of daily living and quality of life were measured.

RESULTS: After each nerve block session, the subjects reported significant improvement in their levels of pain, depression and anxiety. They also reported improvements in their quality of life and in their ability to participate in activities of daily living. CONCLUSIONS: Repeated (palliative) nerve blocks appear to be a useful modality in the armamentarium of pain control techniques for patients with chronic intractable headache and neck ache of cervical origin.

Key Words: Chronic headache; Chronic neck ache; Chronic neck pain; Cervicogenic headache; Nerve blocks; Repeated nerve block

\section{Anesthésie palliative par blocage nerveux pour céphalée et cervicalgie irréductibles chroniques, pratiquée sur 100 patients : étude descriptive}

\begin{abstract}
OBJECTIF : Vérifier si le blocage nerveux palliatif (à répétition) sur une période prolongée s'avère un traitement bénéfique chez les patients souffrant de céphalée et de cervicalgie irréductibles chroniques.

SUJETS ET MÉTHODE : Cent patients soumis à une anesthésie palliative par blocage nerveux dans le cadre de leur traitement ont rempli un questionnaire d'entrevue dirigée. Un diagnostic de céphalée d'origine cervicale a été posé dans tous les cas. On a mesuré les changements notés dans l'évaluation de la douleur, de la dépression, de l'anxiété, des activités de la vie quotidienne et de la qualité de vie.

RÉSULTATS : Après chaque séance d'anesthésie, les patients ont fait état d'une diminution sensible de la douleur, de la dépression et de l'anxiété. Ils ont également signalé une amélioration de leur qualité de vie et de leur capacité à participer à des activités de la vie quotidienne. CONCLUSION : L'anesthésie palliative (à répétition) par blocage nerveux semble une technique valable de soulagement de la douleur chez les patients souffrant de céphalée et de cervicalgie irréductibles chroniques d'origine cervicale.
\end{abstract}


$\mathrm{T}$ he usual practice in specialists' clinics for the management of chronic head and neck pain often fails to provide adequate relief. Traditional treatments such as antidepressants, anticonvulsants and anti-inflammatories, as well as opioids and psychotherapy, provide some relief to some patients. However, significant residual pain often persists in many patients. These patients report almost constant pain with markedly decreased activities of daily living (ADLs) and markedly decreased quality of life.

Saadeh and Taylor (1), Gawel and Rothbart (2), and Caputi and Firetto (3) have shown that repeated nerve blocks can decrease pain for long periods of time. New modalities are being used to try to decrease chronic pain on a permanent or semipermanent basis. These technologies include psychological counselling for pain control (4), spinal cord stimulation (5), continuous opioid infusion with pumps (6) and longacting local anesthetics such as butyl-p-aminobenzoate (butamben) (7). These modalities are by and large unavailable in Canada and in Europe. In the United States, some insurance companies cover the costs of these technologies.

Several pain management clinics have noted that repeated regular nerve blocks together with the usual pharmacological and psychological modalities provide good control of pain in a subset of patients. In 1991, Gawel and Rothbart (2) developed a protocol of performing weekly nerve blocks for three to six sessions and then following the patient's response. In many cases, the patients' pain and medication use decreased significantly. Therefore, it became reasonable to repeat the blocks approximately every three months or so. Over the years, some patients found that they could not remain comfortable for the three-month period and that the pain began to return after a few weeks. Thus, some practices gradually evolved to where nerve blocks were performed on a more frequent basis.

In recent years, the practice at the Rothbart Pain Management Clinic, North York, Ontario, has been to perform nerve blocks on a weekly, twice monthly or once monthly basis as required by the patient (provided that it was found to be medically appropriate) in a subset of patients who benefited. The regimen of repeated nerve blocks has now been carried out in some patients for five to eight years or more. It was observed that this regimen helped control the pain and increased ADLs and quality of life.

The present paper is a retrospective survey of the outcomes of those patients.

\section{Selection criteria}

\section{SUBJECTS AND METHODS}

Patients with the following criteria were selected.

- Cervicogenic headache diagnosed according to the criteria of the International Association for the Study of Pain (8).

- Constant, severe, incapacitating daily headaches by patient report.

- Nerve blocks used were occipital blocks, supraorbital blocks, paravertebral blocks and spinal accessory blocks. All patients had some or all of these nerve blocks as required to relieve their pain. The occipital blocks were performed by using a landmark at the lateral border of the trapezius muscle in its attachment to the nuchal line. This point is immediately medial to the aponeurosis connecting the origin of the trapezius and sternomastoid muscles. Four to $6 \mathrm{~cm}^{3}$ of $0.375 \%$ bupivacaine hydrochloride (Marcaine, Sanofi, Canada) was used. The lesser occipital nerve was also anesthetized by moving approximately $2.5 \mathrm{~cm}$ laterally. The paravertebral blocks were performed as described by Wall and Melzack (9). Marcaine $0.375 \% 1.5 \mathrm{~cm}^{3}$ was used at each level. Supraorbital blocks were performed as described by Moore (10). Marcaine $0.375 \% 1.0$ to $1.5 \mathrm{~cm}^{3}$ was used.

Furthermore, because the repeated nerve blocks were used only as a last resort when all other modalities failed to provide good pain relief, the following criteria also applied.

- The patients had undergone x-rays, computer-assisted tomography scans and/or magnetic resonance imaging scans. Cervical facet diagnostic blocks were performed as necessary. Where positive, the patients had undergone facet joint rhizolysis. The results had been mixed, possibly because of outmoded techniques (11).

- The patients had been treated with the usual pain medications, including nonsteroidal anti-inflammatory drugs, antimigraine drugs and antidepressants. Many patients had also been and were still on opioids of varying strengths.

- Most patients had received psychotherapy, and some were still continuing psychotherapy. However, none had received cognitive or behaviour modification therapy; these are difficult to obtain for most patients because they are not readily available for most patients in Canada.

- All patients had received a course of physiotherapy at least once (and in many patients several times) during the course of their chronic pain.

\section{Subjects}

A sample of convenience was used for this study. The hundred patients were selected in the following manner: three physicians in the clinic who were treating patients receiving repeated blocks on a once-weekly or twice-monthly or oncemonthly basis were asked to submit the names of patients who fulfilled the above-noted selection criteria. The head nurse then took the list, which comprised 128 patients in no particular order, and telephoned patients until the requisite one hundred patients agreed to participate in the study. Altogether, one hundred and nine patients were approached before the requisite number was recruited. The one hundred 
participants were all patients with a diagnosis of chronic cervicogenic headache. They completed a structured interview questionnaire. The subjects experienced daily headaches and were participating in a program of ongoing palliative nerve blocks. Blocks were administered on a weekly or biweekly basis or less frequently as required. Thirty-one subjects were male and sixty-nine were female. Fifty subjects were married; 19 were single and had never been married. Thirteen were currently separated, 14 were divorced and four were widowed. Twenty-five subjects were college graduates, and 23 had completed some college. An additional 25 had completed high school.

For patients in the sample, aggregate employment status had altered dramatically since the onset of pain. Before the pain, 78 were employed on a full-time basis and an additional six were employed part-time. The remainder of the patients were unemployed, homemakers, students, retired or disabled. At the time of the study, only 13 were employed fulltime. The number of subjects working part-time increased slightly to nine. As might be expected, the number of subjects who described themselves as disabled was much higher. Sixty subjects reported that they were disabled at the time of the study.

Forty-five subjects in this study had been injured in a motor vehicle accident. Nineteen had been injured at work. Another nine had been injured in another type of accident. Some of the patients had experienced a slow, progressive onset of pain. Four had developed chronic pain after surgery. Thirteen had experienced an acute onset of pain of an unknown cause. In the majority of these cases, an old injury to the neck, not temporally related to the onset of pain, was suspected as the cause of pain.

On average, the subjects in this sample had been in pain for 12.4 years. There was some variation in the duration of pain when analyzing the subjects by cause of the pain. The patients who had suffered a definable injury had been in pain a mean of 11.4 years. Mean time since the onset of pain for subjects with acute onset of pain of unknown cause was 17.2 years. Subjects whose pain began after surgery had been in pain for an average of 11.7 years.

There was a wide variation in the duration of nerve block treatments in this study. The mean duration was 48.5 months (range three to 112 months; median 41 months). No long term side effects were noted. No skin damage at injection sites was seen.

\section{Measures}

After informed consent was obtained, a structured interview questionnaire was administered by members of the nursing staff at the clinic where treatment was provided. The questionnaire measured a variety of demographic variables and also measured the patients' self-rating of pain, anxiety and depression, both during the time they experience unrelieved pain and during the period of pain relief obtained after the administration of palliative nerve blockade. Patients were asked to rate their level of pain immediately before the nerve block, using the standard visual analogue scale of zero to 10 , where 10 means worst pain and zero means no pain. Similar data were collected using the same zero to 10 scale during the period of pain relief after the blocks. The same patient's selfreport convention was used to measure the patient's subjective experiences of pain, depression and anxiety before and after the blocks. Additional items questioned the subjects regarding the period of time for which patients received pain relief after the administration of palliative blocks. These original items were developed specifically for use in this study.

The Oswestry Disability Index (12) was originally developed to measure ADLs in patients with low back pain. Since that time, the instrument has been used to measure ADLs with other chronic pain populations. More recently, the change in percentage score on the Oswestry Disability Index has been recommended as a measure of functional restoration (13). This measure is a series of 10 questions covering a range of daily activities such as walking, standing, personal hygiene and sleep. Respondents are offered a range of six responses to each item. These responses essentially range from an indication of no impairment in a particular activity to being virtually unable to participate in the activity of interest.

Subjects in this study were asked to respond to the questions on the Oswestry Disability Index to assess the subject's ability to participate in ADLs during periods of unrelieved pain and during the periods of pain relief provided by the blocks. Two scores were then calculated for each respondent. The first score is an indicator of the degree of impairment in ADLs during periods of unrelieved pain. The second score is an indicator of impairment in ADLs during the period of relative relief of pain. These two scores were then used to calculate the percentage of change in ADLs, which served to indicate the degree of functional restoration provided by the palliative nerve blocks. Items from the visual analogue scale to assess subjects' perceptions of their quality of life were also included in the questionnaire. These items used the zero to 10 scale, as is conventionally used.

\section{RESULTS}

The subjects reported significant reductions in their levels of pain after nerve blocks. The mean preblock pain level was 8.6 on a scale of zero to 10 . The mean pain level reported after nerve blocks was $2.3 \pm 1.6$ (SD 1.3). A two-sample test of dependent means revealed that the difference in mean pain scores was significant at the 0.01 level (Figure 1).

A two-sample test of dependent means was also used to analyze the results of the subjects' self-report of depression and anxiety. The mean preblock depression rating was $7.3 \pm 3.1(\mathrm{P}=0.01)$. The mean depression rating after blocks was $2.5 \pm 2.3(\mathrm{P}=0.01)$. For self-reported anxiety, the score before the blocks was $6.6 \pm 3.3(\mathrm{P}=0.01)$. Mean score for anxiety level after blocks was 2.2 $2.2(\mathrm{P}=0.01$ ) (Figures 2,3).

The subjects were also asked about the length of time, on average, that they received at least moderate relief of their pain. The mean period of effective pain relief reported was 7.15 days. The subjects who came approximately weekly re- 


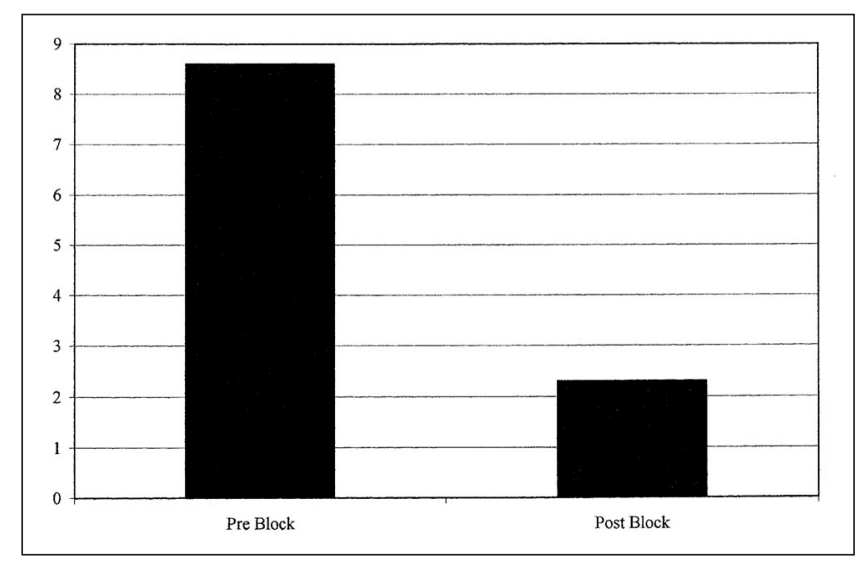

Figure 1) Differences in retrospective pain rating. Patients reported that, on average, their pain dropped from 8.6 before the nerve block to a mean of 2.3 after the nerve block

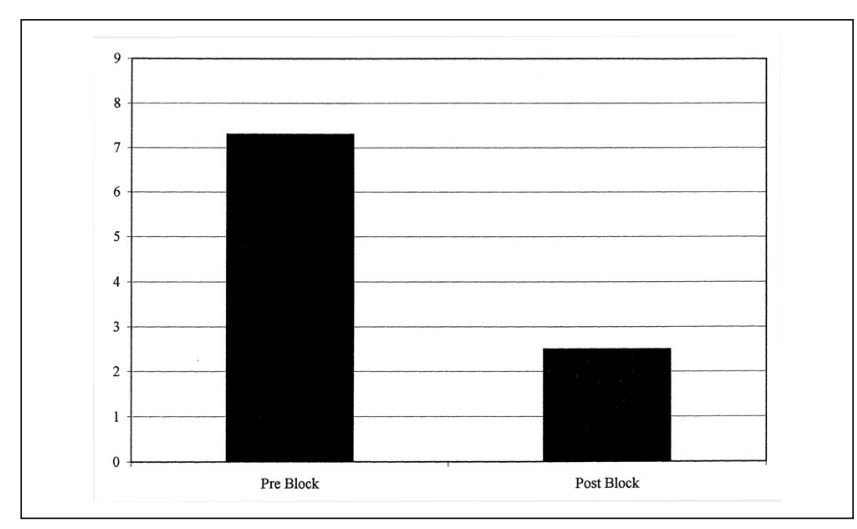

Figure 2) Differences in retrospective depression rating. The mean for self-reported depression before the nerve block was 7.3. This rating dropped to a mean of 2.5 during the pain relief after the nerve block

ceived at least moderate pain relief for two to four days. Those coming approximately every three weeks achieved significant pain relief for seven to 10 days. As might be expected, the patients who had shorter relief were the ones who requested more frequent nerve blocks. Because the blocks are administered to improve the patient's quality of life and to allow them to be more active, the patients were also asked to estimate the degree to which their level of functioning and quality of life improved as a result of the blocks. They were offered the following responses.

- Decrease in quality of life

- No improvement in quality of life

- Slight improvement of quality of life

- Moderate improvement of quality of life

- Marked improvement of quality of life

- Complete restoration of quality of life

Participation in ADLs was assessed using the same six ratings.

No subjects reported that their ability to complete ADLs was compromised or unchanged as a result of the blocks.

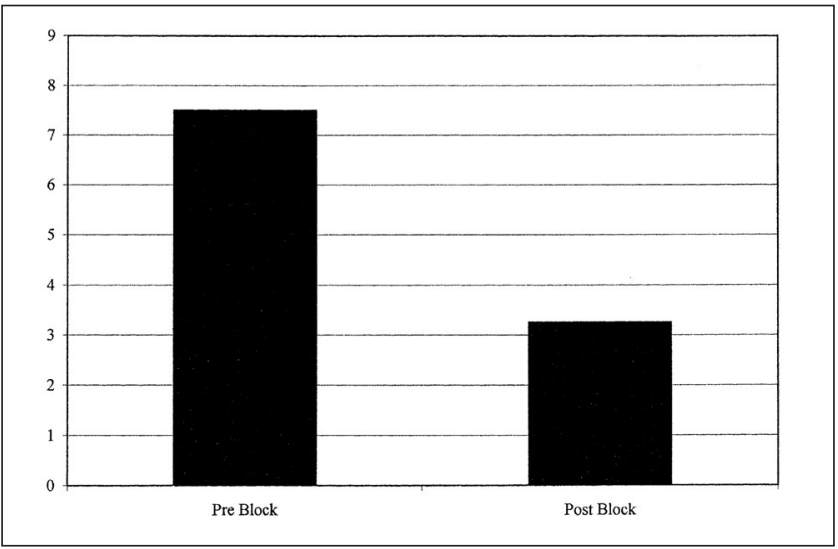

Figure 3) Differences in retrospective anxiety level. Patients' selfreported anxiety level decreased from a mean of 6.6 before the nerve block to a mean of 3.2 after the nerve block

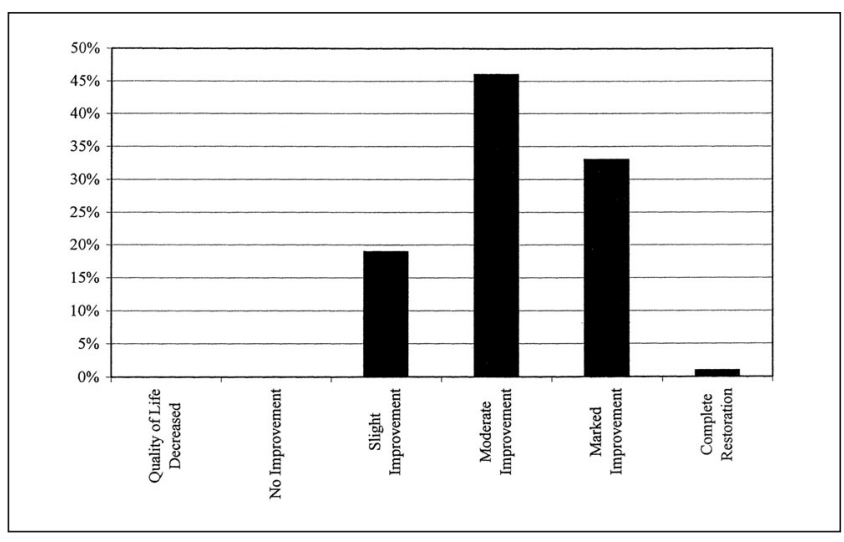

Figure 4) Differences in activity of daily living rate. Improvement in activities of daily living with palliative nerve blocks as reported by subjects

Nineteen subjects reported only slight improvement in participation in ADLs. Forty-six reported moderate improvement in ability to participate in ADLs, and 30 reported that their ADLs were markedly improved. Two subjects reported that they experienced a period of complete return of functioning after the palliative nerve block (Figure 4).

\section{Effects on quality of life}

None of the subjects thought that their quality of life was decreased as a result of the nerve blocks. Five subjects reported no improvement. Twenty-three reported that their quality of life was slightly improved by the blocks. Thirty thought that they experienced moderate improvement in quality of life with nerve blocks. Forty-one experienced a marked increase in quality of life, while one subject thought that quality of life was restored to the prepain level (Figure 5).

Scores on the Oswestry Disability Index are reported below. Respondents with relatively low scores purportedly have relatively low levels of disability. Respondents with higher scores generally have more levels of disability. Fairbank et al (12) offered the following interpretation of these scores. 
- 0 to 20 : minimal disability

- 20 to 40: moderate disability

- 40 to 60: severe disability

- 60 to 80: crippled

- 80 to 100: bedbound or expressing great pain

Because these classifications are not mutually exclusive, the following slightly modified classification was used for this study.

- 0 to 20: minimal disability

- 21 to 40: moderate disability

- 41 to 60: severe disability

- 61 to 80: crippled

- 81 to 100 : bedbound or expressing great pain

\section{Oswestry Disability Index}

The mean Oswestry Disability Index score $(12,13)$ for this sample during periods of unrelieved pain was 56.2, placing the mean for this sample in the upper level of the severe disability category. The mean score for the period of relative pain relief supplied by the blocks was 27.6, placing the mean score in the lower portion of the moderate disability category. In fact, the mean change in score was 28.6. The range of scores indicating improvement in disability rating varied from a low of 4.0 to a high of 56.0. None of the subjects reported a reduction in ability to complete their daily activities after the blocks.

\section{DISCUSSION}

The results demonstrated significant decreases in pain, depression and anxiety. In addition, ADLs increased markedly or moderately in $76 \%$ of patients, and quality of life increased markedly or moderately in $71 \%$ of patients.

This descriptive study suggests that repeated nerve blocks, when used in addition to the standard medications such as antidepressants, anti-inflammatories, anticonvulsants, psychological counselling and opioids, are beneficial for the patient with chronic headache or neck ache.

Ideally, one would hope to find the pain generator (or generators) by using diagnostic blocks, and then perform surgical procedures such as facet rhizotomies, or discotomy and fusion, when diagnostic blocks are positive. However, in practice, it is very difficult to obtain these treatments. There is some evidence of benefit from facet rhizolysis (11). Lord et al (11) pointed out that at least 12 lesions need to be performed at each level to be sure of successful denervation of the facet joint. However, most physicians in Canada perform only one lesion. The results, therefore, tend to be quite mixed. There is no evidence for the benefit of discotomy and fusion. Thus, it appears that palliation may be the appropriate way to approach management of patients, even when their

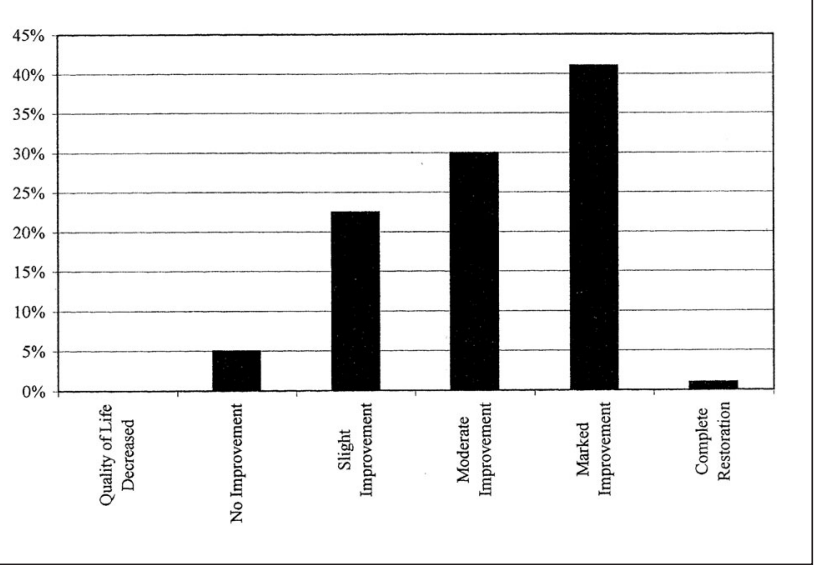

Figure 5) Differences in quality of life rating. Improvement in quality of life with palliative nerve blocks as reported by subjects

pain has organic causes such as facet damage or disc damage. Such palliation by repeated nerve blocks appears to be a reasonable and appropriate approach in managing patients for whom surgery and other modalities have failed or are unavailable.

It was of particular interest that the average duration of a good decrease in pain after nerve blocks was 7.15 days. It is well recognized that, in physiologically normal situations (eg, injection of mandibular or maxillary nerves in dental patients), the duration of analgesia is only a few hours as described in works on regional anesthesia (14). However, in our cases, nerve blocks were performed on damaged nervous systems - the damage being either peripheral or central or both. Our results have been duplicated by other pain physicians who have used repeated nerve blocks. A number of researchers have discussed reasons for this phenomenon $(15,16)$. Clearly, this whole area requires further study. It may lead to new ways of providing longer duration of pain relief in patients with chronic pain.

We recognize that there are limitations inherent in this study, the most obvious being that this was not a controlled study. Thus, we were unable to take into account the placebo effect. However, because the relief continues over a number of years while receiving the nerve blocks, the placebo effect may be fairly small. There was clearly a selection bias. Our observations indicate that there are four broad groups of different responders to nerve blocks: the first group does well for months or years after a few nerve blocks; the second group obtains little benefit and stops quite soon; the third group does well with a combination of medication and/or therapy and repeated nerve blocks, and often evolves to be comfortable with medications and only infrequent nerve blocks; and the fourth group responds well to nerve blocks and requests repeated regular nerve blocks as a means of good pain control. The patients we chose were all in the fourth category, ie, they responded well to the experience. A randomized, controlled study needs to be undertaken to substantiate the current findings and tentative conclusions. 


\section{REFERENCES}

1. Saadeh HA, Taylor FB. Sustained headache syndrome associated with occipital nerve zones. Headache 1987;27:201-4.

2. Gawel M, Rothbart P. Occipital nerve block in the management of headache and cervical pain. Cephalalgia 1992;12:9-113.

3. Caputi CA, Firetto V. Therapeutic blockade of greater occipital and supraorbital nerves in migraine patients. Headache 1997;37:174-9.

4. Johansson C, Dahl J, Jannert M, Melin L, Andersson G. Effects of a cognitive-behavioral pain-management program. Behav Res Ther 1998;36:915-30.

5. Devulder J, DeLatt M, Van Bastelaere M, Rolly G. Spinal cord stimulation: a valuable treatment for chronic failed back surgery patients. J Pain Symptom Manage 1997;13:296-301.

6. Hassenbusch SJ, Stanton-Hicks M, Covington EC, Walsh JG, Guthrey DS. Long-term intraspinal infusions of opioids in the treatment of neuropathic pain. J Pain Symptom Manage 1993;10:527-43.

7. Shulman M, Ivankovich AD, Braverman B, Lubenow T. Treatment of chronic intractable back pain with $10 \%$ Butamben suspension. Reg Anesth 1992;17(Suppl):87.

8. Merskey H, Bogduk N, eds. Classification of Chronic Pain: Description of Chronic Pain Syndromes and Definitions of Pain Terms, 2nd edn. Seattle: IASP Press, 1994.
9. Wall PD, Melzack R, eds. Textbook of Pain. Edinburgh: Churchill Livingstone, 1984.

10. Moore DC. Regional Block: A Handbook for Use in the Clinical Practice of Medicine and Surgery, 4th edn. Springfield: Charles C Thomas, 1979.

11. Lord SM, Barnsley L, Wallis BJ, McDonald GJ, Bogduk N. Percutaneous radio-frequency neurotomy for chronic cervical zygapophyseal-joint pain. N Engl J Med 1996;335:1721-6.

12. Fairbank JCT, Couper J, Davies JB, O’Brien JP. The Oswestry Low Back Pain Disability Questionnaire. Physiotherapy 1980;271:66.

13. Little DG, MacDonald D. The use of the percentage change in Oswestry Disability Index score as an outcome measure in lumbar spinal surgery. Spine 1994;19:2139-43.

14. Cousins M, Bridenbaugh P, eds. Neural Blockade in Clinical Anaesthesia and Management of Pain, 3rd edn. Philadelphia: Lippincott Williams \& Wilkins Publishers, 1998:1135-45.

15. Arner S, Lindblom U, Meyerson BA, Molander C. Prolonged relief of neuralgia after regional anesthetic blocks. a call for further experimental and systemic clinical studies. Pain 1990;43:287.

16. Mao J, Chin L. Systemic lidocaine for neuropathic pain relief. Pain 2000;87:7-17 


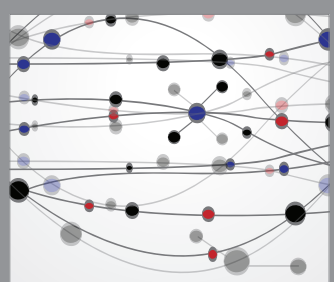

The Scientific World Journal
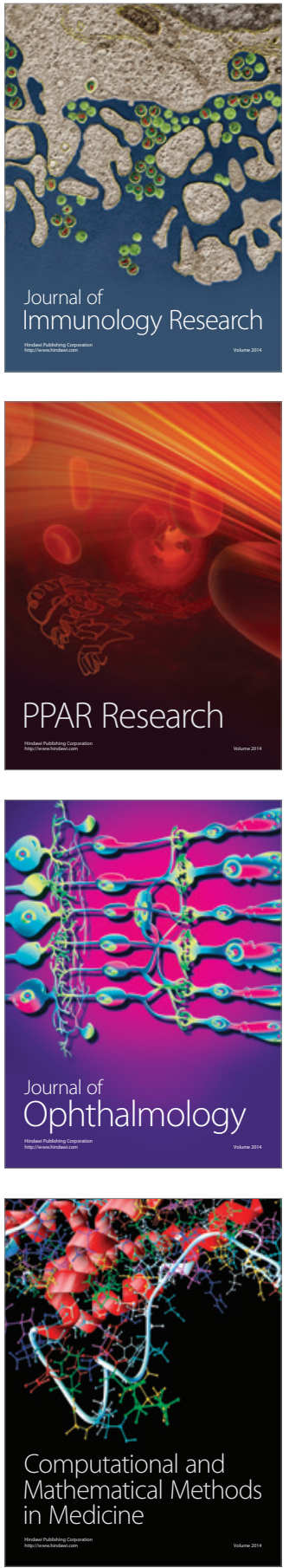

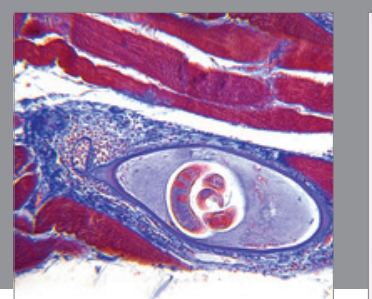

Gastroenterology Research and Practice

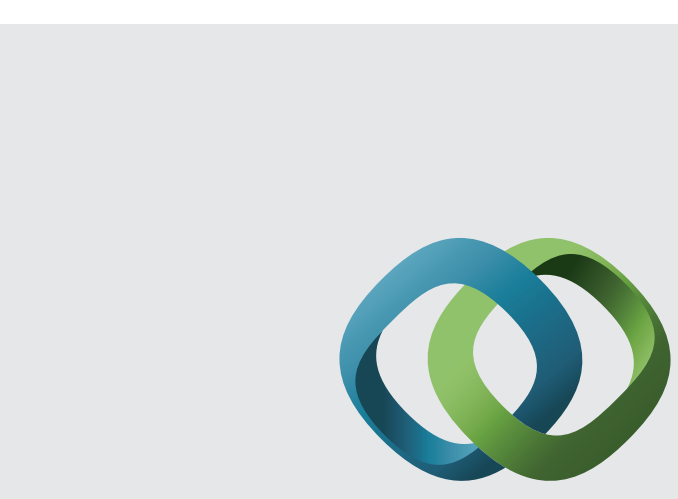

\section{Hindawi}

Submit your manuscripts at

http://www.hindawi.com
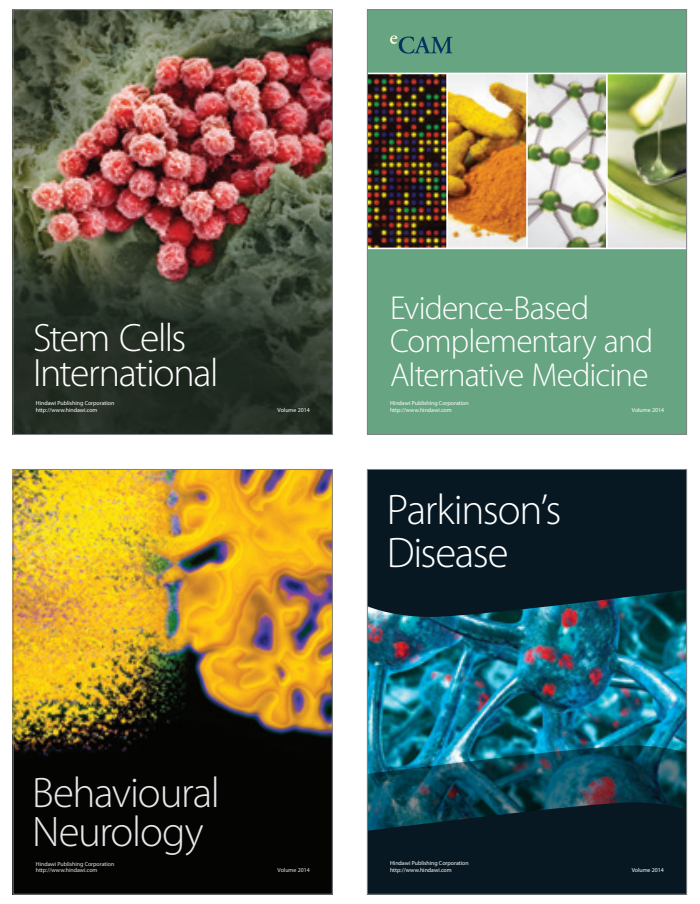
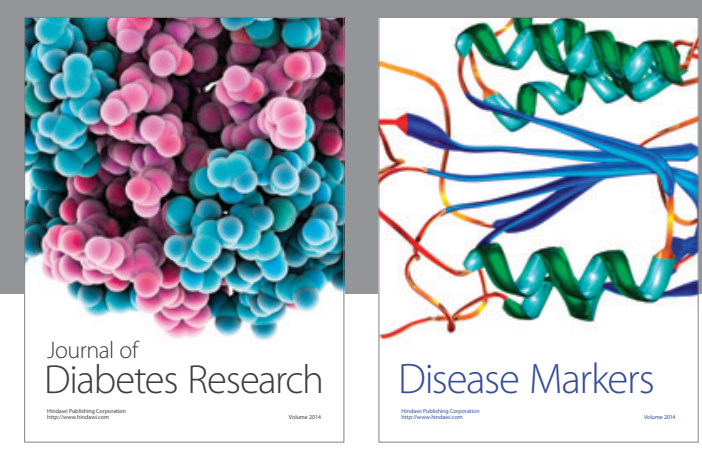

Disease Markers
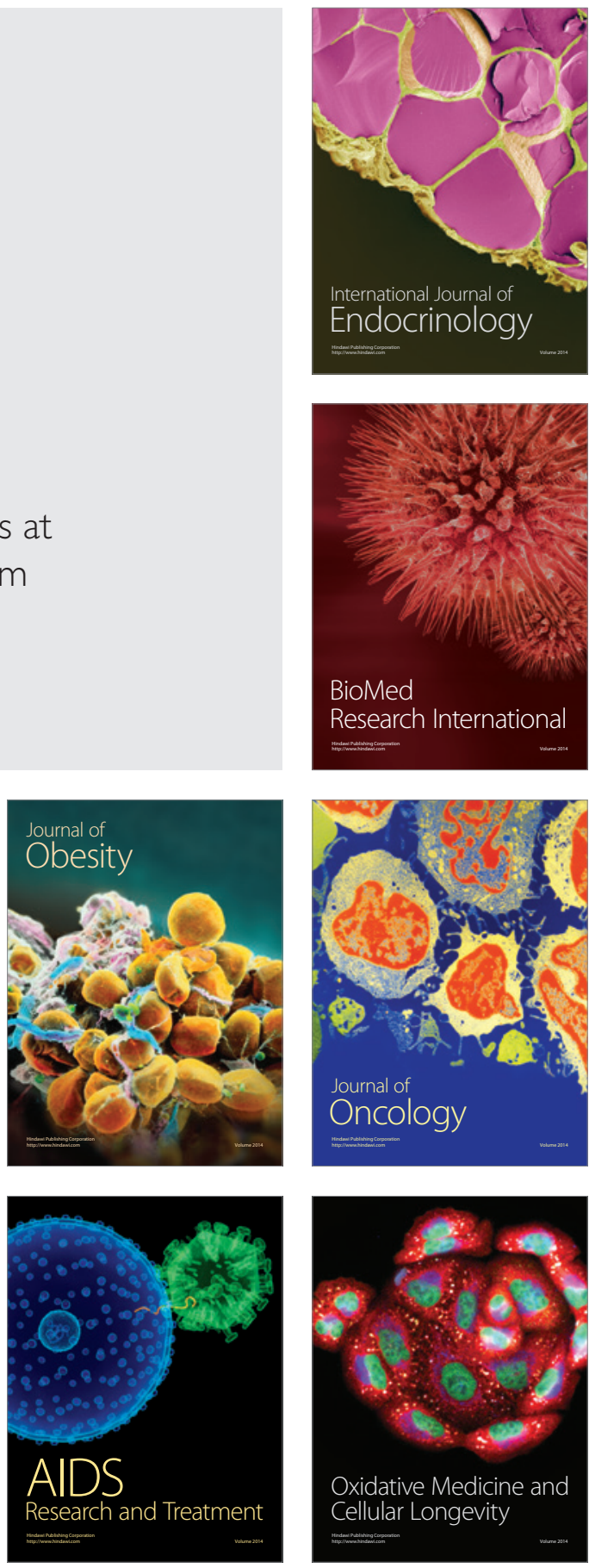